\title{
Arginine Therapy for Lung Diseases
}

\author{
Jeremy A. Scott ${ }^{1 \star}$, Harm Maarsingh ${ }^{2}$, Fernando Holguin ${ }^{3}$ and Hartmut Grasemann ${ }^{4}$ \\ ${ }^{1}$ Occupational and Environmental Health, Dalla Lana School of Public Health, University of Toronto, Toronto, ON, Canada, \\ ${ }^{2}$ Department of Pharmaceutical Sciences, Lloyd L. Gregory School of Pharmacy, Palm Beach Atlantic University, West Palm \\ Beach, FL, United States, ${ }^{3}$ Division of Pulmonary Sciences and Critical Care, University of Colorado, Aurora, CO, United States, \\ ${ }^{4}$ Division of Respiratory Medicine, Department of Paediatrics and Translational Medicine, Research Institute, The Hospital for Sick \\ Children, Toronto, ON, Canada
}

Nitric oxide (NO) is produced by a family of isoenzymes, nitric oxide synthases (NOSs), which all utilize L-arginine as substrate. The production of $\mathrm{NO}$ in the lung and airways can play a number of roles during lung development, regulates airway and vascular smooth muscle tone, and is involved in inflammatory processes and host defense. Altered L-arginine/NO homeostasis, due to the accumulation of endogenous NOS inhibitors and competition for substrate with the arginase enzymes, has been found to play a role in various conditions affecting the lung and in pulmonary diseases, such as asthma, chronic obstructive pulmonary disease (COPD), cystic fibrosis (CF), pulmonary hypertension, and bronchopulmonary dysplasia. Different therapeutic strategies to increase L-arginine levels or bioavailability are currently being explored in pre-clinical

OPEN ACCESS

Edited by:

Salvatore Salomone,

University of Catania, Italy

Reviewed by:

Claudio Sorio,

University of Verona, Italy

Kewal Asosingh,

Cleveland Clinic, Cleveland, $\mathrm{OH}$,

United States

*Correspondence:

Jeremy A. Scott

jeremy.scott@utoronto.ca

Specialty section:

This article was submitted to Experimental Pharmacology and Drug

Discovery,

a section of the journal

Frontiers in Pharmacology

Received: 09 November 2020

Accepted: 04 February 2021

Published: 23 March 2021

Citation:

Scott JA, Maarsingh H, Holguin F and Grasemann H (2021) Arginine Therapy for Lung Diseases.

Front. Pharmacol. 12:627503. doi: 10.3389/fphar.2021.627503 and clinical studies. These include supplementation of L-arginine or L-citrulline and inhibition of arginase.

Keywords: airway hyperresponsiveness, remodeling, chronic obstructive pulmonary desease, cystic fibrosis, Pulmonary hypertension, asthma, asymmetric dimethyl arginine

\section{INTRODUCTION}

Nitric oxide (NO) is formed by Nitric oxide synthase (NOS) enzymes, in a two-step reaction that uses oxygen and the amino acid, L-arginine, to form $\mathrm{NO}$ and L-citrulline. L-Citrulline can be recycled back to L-arginine (Curis et al., 2005), and this L-citrulline recycling has been shown to be particularly important in conditions of reduced substrate availability for NOS, for instance when NOS expression is increased or in the presence of increased endogenous NOS inhibitors (Wu and Morris, 1998; Winnica et al., 2017) Figure 1. NOS monomers, consisting of an oxygenase and a reductase domain, form a homodimer complex at the oxygenase domains that is important for normal NOS functioning. All three of the NOS isozymes can become uncoupled under conditions of low L-arginine availability, low levels of the cofactor tetrahydrobiopterin $\left(\mathrm{BH}_{4}\right)$, increased levels of inhibitors or oxidative stress (Förstermann and Sessa, 2012; Berka et al., 2014). Uncoupled NOS produces superoxide $\left(\mathrm{O}_{2}{ }^{-}\right)$from oxygen which reacts with $\mathrm{NO}$ to form peroxynitrite $\left(\mathrm{ONOO}^{-}\right)$, thus potentiating the uncoupling of NOS by lowering the levels of $\mathrm{BH}_{4}$, disrupting the NOS homodimer, and oxidizing the zinc-containing core (Münzel et al., 2005; Förstermann and Sessa, 2012). Uncoupling of NOS thus results in a shift of NO production to the formation of peroxynitrite and oxidative stress. Increasing the bioavailability of L-arginine restores NO production and inhibit $\mathrm{O}_{2}^{-}$production by NOS.

The intracellular activity of all NOS isoenzymes, i.e., the so called constitutively expressed NOS1 (neuronal; nNOS) and NOS3 (endothelial; eNOS) isoforms, as well as the inducible NOS (NOS2; iNOS), is regulated by the availability of substrate L-arginine, which is determined by 


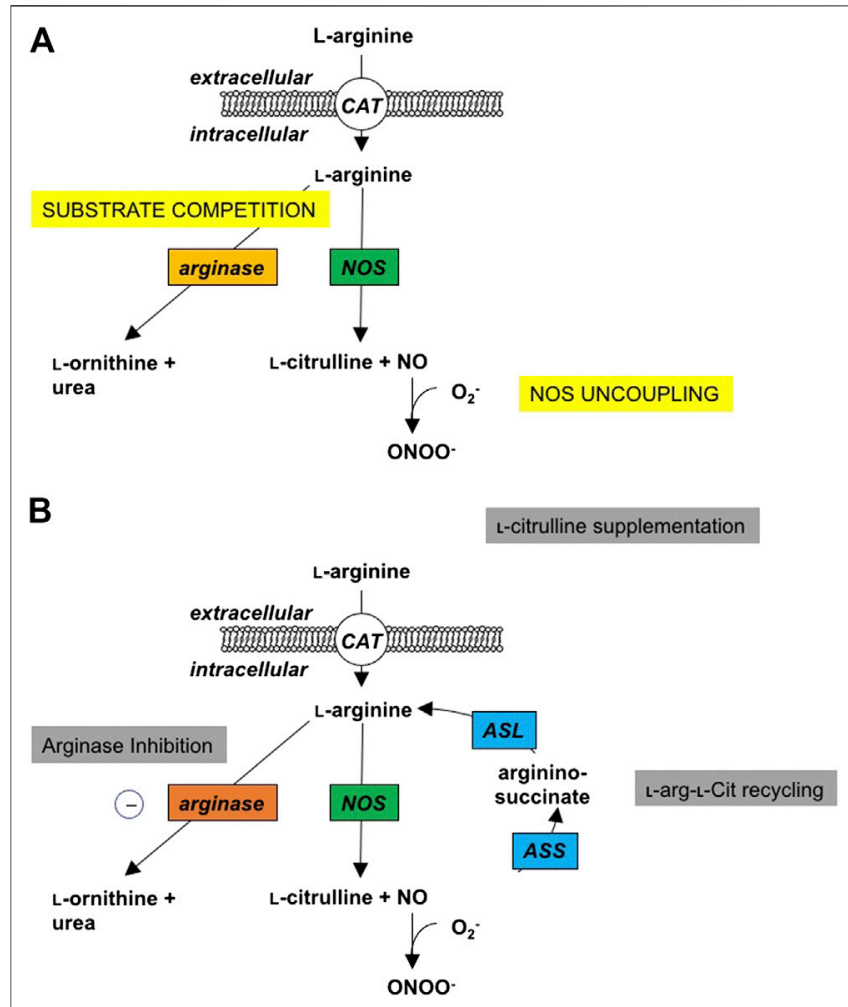

FIGURE 1 | Changes in L-Arginine metabolism in disease and potential interventions. (A) Under normal physiologic conditions, cationic amino acid transporters (CAT) transport L-arginine into the cell where it can be metabolized by nitric oxide synthase (NOS) to $\mathrm{NO}$ and L-citrulline in a two-step process with $\mathrm{N} \omega$-hydroxy-L-arginine (NOHA) as intermediate. Under pathophysiologic conditions, excess induction of the arginase isozymes can lead to increased competition for substrate, thus limiting the $L$-arginine available for the NOS isozymes, and leading to NOS uncoupling and the production of peroxynitrite. (B) As potential sites of intervention, local or systemic administration of arginase inhibitors can increase the cellular bioavailability of L-arginine for the NOS isozymes and improve the production of NO. Supplemental L-citrulline can be recycled to L-arginine by argininosuccinate synthase (ASS) and argininosuccinate lyase (ASL), with argininosuccinate as an intermediate; thus, also improving intracellular bioavailability of L-arginine to improve $\mathrm{NO}$ production.

cellular uptake (Closs et al., 1997), competition with other L-arginine-metabolizing enzymes, particularly the arginase isozymes (arginase I and II) (Wu and Morris, 1998), the presence of endogenous NOS inhibitors, including asymmetric (ADMA) and symmetric dimethylarginine (SDMA) and monomethylarginine (MMA) (Leiper et al., 2007), and L-citrulline/L-arginine recycling (Curis et al., 2005). Methylation of arginine residues in proteins is catalyzed by protein arginine methyltransferases (PRMTs). These methylated arginine derivatives (the endogenous NOS inhibitors ADMA, SDMA and MMA) are liberated as a result of protein degradation. The L-arginine:ADMA ratio (BodeBöger et al., 2007) provides some insight into NOS activity alterations in pulmonary disease (Holguin et al., 2013; Scott and Grasemann, 2013), with a higher ratio indicating the more normal homeostatic circumstance.

\section{INCREASING ARGININE AVAILABILITY}

Since reduced L-arginine availability for NOS has been observed in a number of clinical conditions and diseases, different strategies have been explored to increase L-arginine or the L-arginine:ADMA ratio. L-Arginine is a semi-essential amino acid, which is supplied in the diet and also synthesized from L-citrulline, mainly in the intestinal mucosa ( $\mathrm{Wu}$ and Morris, 1998). The enzymatic conversion of L-citrulline to L-arginine mainly takes place in the kidney (Curis et al., 2005). In most cells, L-arginine requirements are met primarily by uptake of extracellular L-arginine via specific transport systems (Closs et al., 1997). The efficacy of oral L-arginine to increase L-arginine availability for NOS and subsequently NO formation is limited by a significant first-pass effect. Interestingly, this is not the case for L-citrulline. Oral L-citrulline therefore results in greater increases of circulating L-arginine (via the recycling pathway) and longer circulation time than L-arginine supplementation (Curis et al., 2005; Suzuki et al., 2017).

\section{Asthma}

Elevated fractional exhaled NO (FeNO) in asthmatics is due to activity of NOS2, which is induced during inflammation, in the airways (Ricciardolo et al., 2004). Positive correlations between FeNO, NOS2 expression in airway epithelial and inflammatory cells, airway eosinophilia, and airway hyperresponsiveness (AHR) have been described (Meurs et al., 2003). Reduced L-arginine availability appears to play a key role in allergeninduced AHR, but protein expression of the cationic amino acid transporters CAT1 and CAT2, which facilitate L-arginine uptake, have both been found to be unaltered in lung tissue from asthma subjects (North et al., 2009). However, NOS2 expression in bronchial biopsies from people with asthma was associated with increased presence of nitrotyrosine (Saleh et al., 1998)and $\mathrm{ONOO}^{-}$content correlated with $\mathrm{FeNO}$ and AHR suggesting uncoupling of $\mathrm{NOS}$ and subsequent $\mathrm{ONOO}^{-}$related airway inflammation in asthma (Saleh et al., 1998). One contributing factor to this could be substrate limitation due to competition for substrate by arginase, which converts L-arginine to L-ornithine and urea. The expression and activity of arginase is increased in lung tissue and airways obtained from various animal models of acute and chronic asthma, as well as in asthmatic patients (Merus et al., 2002; Zimmermann et al., 2003; Maarsingh et al., 2008a; North et al., 2009; Maarsingh et al., 2011); specifically, arginase I expression is upregulated in airway epithelial cells from asthmatics (Zimmermann et al., 2003), and in animal models (North et al., 2009), which may directly affect NO production in the airways. Furthermore, mitochondrial arginase II expression has also been reported to be upregulated in asthma, which may more broadly affect cellular energetics (Xu et al., 2016; Asosingh et al., 2020). Increased serum arginase activity and reduced plasma L-arginine levels have been observed in people experiencing asthma attacks (Morris et al., 2004). The relevance of reduced plasma L-arginine levels to asthma is supported by the finding that allergen-induced AHR in mice was higher in mice that had 50\% lower circulating L-arginine 
levels due to genetic overexpression of arginase I in enterocytes (Cloots et al., 2018). Increased arginase also contributes to NOS impairment by reducing the L-arginine:ADMA ratio (North et al., 2009; Scott et al., 2011; Scott et al., 2014b) and by promoting uncoupling of NOS (Mabalirajan et al., 2010). Increased levels of L-ornithine, the product of arginase activity, could also contribute to the observed NO deficiency in asthma by inhibiting cellular L-arginine uptake (Maarsingh et al., 2008a) and by providing substrate for the production of polyamines, which can also act as potent inhibitors of NOS (North et al., 2013).

Both L-arginine and L-citrulline have been shown to reduce AHR in animal models of allergic asthma (De Boer et al., 2001; Maarsingh et al., 2006; Maarsingh et al., 2008b; Maarsingh et al., 2009a; Maarsingh et al., 2009b; Mabalirajan et al., 2010), and L-arginine alone has also been shown to reduce allergen-induced inflammation in mice (Mabalirajan et al., 2010; Zhang et al., 2015). Oral and inhaled L-arginine increased FeNO in healthy subjects and asthmatic (Kharitonov et al., 1995; Sapienza et al., 1998), but did not affect AHR to histamine (De Gouw et al., 1999). Oral L-arginine supplementation (6-8 g/day) in patients with mild to moderate asthma resulted in an increase in serum $\mathrm{L}$-arginine, ADMA and L-ornithine compared to placebo but had no effects on FeNO, number of exacerbations, or lung function (Kenyon et al., 2011). In a more recent study, oral L-arginine supplementation in severe asthmatics and low FeNO also did not reduce asthma exacerbation rates. However, the higher plasma L-citrulline levels in this study were associated with increased FeNO (Liao et al., 2020).

The effect of the two arginase isozymes on airway inflammation in allergic asthma has also been studied. Genetic ablation of arginase I in myeloid cells did not affect airway inflammation-or AHR-in mouse models of allergic asthma (Niese et al., 2009; Barron et al., 2013). However, a study in female mice demonstrated that deletion of arginase I in myeloid cells attenuated allergen-induced airway inflammation (Cloots et al., 2017), suggesting gender differences in the role of arginase I in regulating inflammation in asthma. Genetic ablation of arginase II actually further increased allergen-induced airway inflammation in mice (Xu et al., 2017; Asosingh et al., 2020), indicative for a protective role of arginase II in airway inflammation. The use of arginase inhibitors that inhibit both arginase I and II has therefore been cautioned. However, in studies in male guinea pigs, arginase inhibitors have shown to decrease (Maarsingh et al., 2008b; Maarsingh et al., 2011) or not alter (van den Berg et al., 2020) allergen-induced airway inflammation. By contrast, arginase inhibition increased allergen-induced airway inflammation in female mice (Ckless et al., 2008). These findings with arginase inhibitors support a potential gender specific role or arginase $\mathrm{I}$ in allergic inflammation in asthma.

Obesity is a major co-morbidity in asthma and is associated with poor asthma control. Blood samples from obese asthmatics show increased arginase activity, and lower L-arginine:ADMA ratios, leading to uncoupling of NOS, production of $\mathrm{O}_{2}{ }^{-}$as well as oxidative and nitrosative stress (Holguin et al., 2013; Winnica et al., 2017). In a recent clinical trial in obese asthmatics with low FeNO (<30 ppb), oral L-citrulline (15 g/day) supplementation for two weeks increased plasma L-arginine along with the L-arginine: ADMA ratio, increased FeNO, and improved asthma control and lung function, especially in obese females with late-onset asthma (Holguin et al., 2019).

\section{Chronic Obstructive Pulmonary Disease}

Methods for estimating flow-independent airway NO concentrations have suggested that COPD is associated with elevated alveolar NO (Roy et al., 2007). The expression of NOS2 has been shown to be increased in alveolar walls, small airway epithelium, vascular smooth muscle. NOS2 is also increased in sputum macrophages from COPD patients and so is the generation of $\mathrm{ONOO}^{-}$in macrophages and $\mathrm{ONOO}^{-}$ content in exhaled breath condensate from COPD patients (Ichinose el al., 2000; Osata et al., 2009). Other studies in COPD patients have shown that FeNO correlated with preand post-bronchodilator forced expiratory volume in $1 \mathrm{~s}$ (FEV1), and sputum L-ornithine levels correlated with L-arginine and ADMA concentrations. Arginase activity correlated inversely with total $\mathrm{NO}$ metabolite (NOx) in sputum, and with pre- and post-bronchodilator FEV1 (Scott et al., 2014a). In a different study, ADMA levels in serum correlated with airway resistance, particularly in patients with poor COPD control (Tajti et al., 2017); further suggesting that ADMA in COPD airways results in a functionally relevant shift of L-arginine metabolism towards the arginase pathway. The functional relevance of this was demonstrated in a guinea model where arginase inhibition shifted the L-ornithine: L-citrulline ratio towards L-citrulline and prevented neutrophilia, mucus hypersecretion and collagen synthesis (Pera et al., 2014). Studies in humans with COPD aiming to increase L-arginine availability for NOS are, to our knowledge, currently lacking. Thus similar to asthma, increasing substrate availability for NOS by arginase inhibition, or supplementation of L-arginine or L-citrulline or a combination thereof, may also be feasible in COPD.

\section{Cystic Fibrosis}

Multiple studies have shown that FeNO is decreased in people with cystic fibrosis (CF) (Grasemann et al., 1997; Elphick et al., 2001), and this may contribute to lower lung function and increased infection risk. Mechanisms contributing to low airway NO in CF may include reduced NOS2 expression (Downey and Elborn, 2000), increased metabolism of NO with the formation of $\mathrm{ONOO}^{-}$(Robbins et al., 2000) and retention in airway secretions (Grasemann et al., 1998) and consumption of NO by denitrifying bacteria (Gaston et al., 2002). In addition, CF airway secretions are rich in neutrophil-derived arginase $\mathrm{I}$, as well as ADMA. These factors all lead to lowered airway L-arginine levels and a state of NO-deficiency (Grasemann et al., 2005b; Grasemann et al., 2006b; Grasemann et al., 2011). A recent study suggested that decreased NO formation and increased proteinarginine methylation may be associated with poor nutritional status in people with CF (Brinkmann et al., 2020). Interestingly, the CFTR modulating drug ivacaftor, which improves CFTR function and clinical outcomes including nutritional status, also increases FeNO in treated CF patients (Grasemann et al., 
2015b; Grasemann et al., 2020). Previous studies had shown that increasing L-arginine in CF patients by infusion, inhalation or oral supplementation can increased FeNO, but that only inhaled L-arginine improved lung function (Grasemann et al., 1999; Grasemann et al., 2005a; Grasemann et al., 2006a). Interestingly, a recent study utilizing patient-derived bronchial and nasal cultured epithelial cells, showed that the addition of arginine together with inhibition of arginase activity increased cytosolic NO and enhanced the rescue effect of the CFTR targeting drug ORKAMBI on F508del-CFTR-mediated chloride conductance. The combination of arginine addition with concomitant arginase inhibition also enhanced ORKAMBI-mediated increases in ciliary beat frequency and mucociliary movement. Thus, increasing L-arginine availability for NOS may further increase the efficacy of CFTR modulator therapies (Wu et al., 2019). Another approach to increase L-arginine availability for NOS is through arginase inhibition. Clinical trials are currently underway to study the effect of an oral arginase inhibitor (CB-280) on lung disease in patients with CF (ClinicalTrials.gov: NCT04279769).

\section{Pulmonary Hypertension}

The cause of pulmonary hypertension $(\mathrm{PH})$ is increased vascular resistance in the lung. This often occurs as a consequence of endothelial cell dysfunction, reduced $\mathrm{NO}$, impaired NO-mediated vasodilatory response and/or vascular remodeling (Kaneko et al., 1998; Klinger et al., 2013). The NO deficiency could at least in part be explained by NOS3 uncoupling and increased scavenging of NO due to oxidative stress, and by increased levels of ADMA (Kao et al., 2015; Morris et al., 2005). Increased serum arginase activity and more specifically, endothelial arginase II expression, low plasma L-arginine levels and low 1--arginine:ADMA ratios have been described in patients with both primary and secondary $\mathrm{PH}$ (Morris et al., 2003; Xu et al., 2004; Morris et al., 2005; Kao et al., 2015). Arginase inhibition has been shown to prevent right ventricular hypertrophy in a guinea pig model of COPD (Pera et al., 2014) and reduce the elevated right ventricular systolic pressure in various animal models of $\mathrm{PH}$ (Jiang et al., 2015; Grasemann et al., 2015a; Jung et al., 2017). Arginase inhibition has also been shown to inhibit the hypoxiainduced proliferation of human pulmonary arterial smooth muscle cells (Jiang et al., 2015; Chu et al., 2016), implicating that increased arginase activity could also contribute to vascular remodeling in $\mathrm{PH}$.

Clinical studies in patients with $\mathrm{PH}$ have shown positive effects of L-arginine supplementation (Nagaya et al., 2001; Brown et al., 2018). L-Arginine may also be useful in patients with $\mathrm{PH}$ and sickle cell disease (Morris et al., 2003; Morris, 2014; Morris, 2017). Supplementation with L-citrulline in newborn infants with chronic PH (Fike et al., 2014) and in patients with idiopathic pulmonary arterial hypertension and Eisenmenger Syndrome (Sharif Kashani et al., 2014) have also been shown to result in improved hemodynamics. Recent studies have also suggested that $\mathrm{L}$-citrulline reduces the risk of postoperative $\mathrm{PH}$ in children with congenital heart disease (CHD) undergoing surgery (Smith et al., 2006; Silvera Ruiz et al., 2020).

\section{Chronic Lung Disease/Bronchopulmonary Dysplasia}

Chronic lung disease (CLD) or bronchopulmonary dysplasia (BPD is the major cause of morbidity and mortality in very low birth weight infants (VLBW). BPD is characterized by arrested alveolar development and is complicated by pulmonary hypertension $(\mathrm{PH})$. During lung development, NO has been reported to promote alveolar growth. We have reported changes in the expression of lung arginase throughout the development of experimental $\mathrm{BPD} / \mathrm{PH}$, the inhibition of which and/or abrogation leading to improvement in the $\mathrm{PH}$ phenotype (Belik et al., 2008; Belik et al., 2009). Supplemental inhaled NO (iNO) also ameliorates the BPD phenotype in experimental models and in some premature infants. Lung parenchymal NO-mediated relaxation is impaired in rat neonates exposed to hyperoxia (Sopi et al., 2007), which could be restored by inhibition of the increased arginase activity (Ali et al., 2012), or with supplementation with L-arginine (Ali et al., 2012) or L-citrulline (Sopi et al., 2012). L-Citrulline supplementation prevents hyperoxiainduced lung injury and $\mathrm{PH}$ in newborn rats (Vadivel et al., 2010). A cross-sectional study in neonates reported that L-citrulline levels < $29 \mu \mathrm{mol} / \mathrm{L}$ was associated with BPD/PH (100\% sensitivity and 75\% specificity); thus, monitoring L-citrulline may be used as a screening tool for BPD/PH (Montgomery et al., 2016). In a clinical study in VLBW infants L-arginine supplementation resulted in survival without CLD was significantly higher in the L-arginine-treated compared with the control group (Polycarpou et al., 2013). As noted previously, the oral bioavailability of L-arginine is limited significantly by the first pass effect, and that this can be circumvented by administration of L-citrulline to engage the $\mathrm{L}$-citrulline/L-arginine recycling pathway. As such, there is currently a trial of oral L-citrulline supplementation in preterm infants that aims to determine the safety, efficacy and dosing for the treatment of BPD/PH (ClinicalTrials.gov Identifier: NCT03649932). Thus, there appears promise in the potential for treatment of $\mathrm{BPD} / \mathrm{PH}$ through modification of L-arginine bioavailability in the lung.

\section{SUMMARY}

Dysregulation of Larginine/NO metabolism in the lung and airways can contribute to the development of chronic lung diseases, including asthma, COPD, cystic fibrosis, bronchopulmonary dysplasia and pulmonary hypertension. New work aiming to correct for these dysfunctions by increasing L-arginine availability to NOS, focusing on the provision of supplemental L-arginine and/or L-citrulline, as well as inhibition of the competing enzyme, arginase, may lead to improvements in our understanding of the pathogenesis and treatment of these diseases.

\section{AUTHOR CONTRIBUTIONS}

JS, HM, FH, and HG contributed to the review of the literature, drafting of the original manuscript and editing of the final version. 


\section{REFERENCES}

Ali, N. K., Jafri, A., Sopi, R. B., Prakash, Y. S., Martin, R. J., and Zaidi, S. I. (2012). Role of arginase in impairing relaxation of lung parenchyma of hyperoxia-exposed neonatal rats. Neonatology 101 (2), 106-115. doi:10. $1159 / 000329540$

Asosingh, K., Lauruschkat, C. D., Alemagno, M., Frimel, M., Wanner, N., Weiss, K., et al. (2020). Arginine metabolic control of airway inflammation. JCI Insight 5 (2), e127801. doi:10.1172/jci.insight.127801

Barron, L., Smith, A. M., El Kasmi, K. C., Qualls, J. E., Huang, X., Cheever, A., et al. (2013). Role of arginase 1 from myeloid cells in th2-dominated lung inflammation. PLoS One 8 (4), e61961. doi:10.1371/journal.pone.0061961

Belik, J., Shehnaz, D., Pan, J., and Grasemann, H. (2008). Developmental changes in arginase expression and activity in the lung. Am. J. Physiol. Lung Cell. Mol. Physiol. 294 (3), L498-L504. doi:10.1152/ajplung.00242.2007

Belik, J., Stevens, D., Pan, J., Shehnaz, D., Ibrahim, C., Kantores, C., et al. (2009). Chronic hypercapnia downregulates arginase expression and activity and increases pulmonary arterial smooth muscle relaxation in the newborn rat. Am. J. Physiol. Lung Cell. Mol. Physiol. 297 (4), L777-L784. doi:10.1152/ ajplung.00047.2009

Berka, V., Liu, W., Wu, G., and Tsai, A. L. (2014). Comparison of oxygen-induced radical intermediates in iNOS oxygenase domain with those from nNOS and eNOS. J. Inorg. Biochem. 139, 93-105. doi:10.1016/j.jinorgbio.2014.06.011

Bode-Böger, S. M., Scalera, F., and Ignarro, L. J. (2007). The L-arginine paradox: importance of the L-arginine/asymmetrical dimethylarginine ratio. Pharmacol. Ther. 114 (3), 295-306. doi:10.1016/j.pharmthera.2007.03.002

Brinkmann, F., Hanusch, B., Ballmann, M., Mayorandan, S., Bollenbach, A., Chobanyan-Jurgens, K., et al. (2020). Activated L-arginine/nitric oxide pathway in pediatric cystic fibrosis and its association with pancreatic insufficiency, liver involvement and nourishment: an overview and new results. J. Clin. Med. 9 (6), 2012. doi:10.3390/jcm9062012

Brown, M. B., Kempf, A., Collins, C. M., Long, G. M., Owens, M., Gupta, S., et al. (2018). A prescribed walking regimen plus arginine supplementation improves function and quality of life for patients with pulmonary arterial hypertension: a pilot study. Pulm. Circ. 8 (1), 2045893217743966. doi:10.1177/ 2045893217743966

Chu, Y., XiangLi, X., Niu, H., Wang, H., Jia, P., Gong, W., et al. (2016). Arginase inhibitor attenuates pulmonary artery hypertension induced by hypoxia. Mol. Cel. Biochem. 412 (1-2), 91-99. doi:10.1007/s11010-015-2611-z

Ckless, K., Lampert, A., Reiss, J., Kasahara, D., Poynter, M. E., Irvin, C. G., et al. (2008). Inhibition of arginase activity enhances inflammation in mice with allergic airway disease, in association with increases in protein S-nitrosylation and tyrosine nitration. J. Immunol. 181 (6), 4255-4264. doi:10.4049/jimmunol. 181.6.4255

Cloots, R. H. E., Sankaranarayanan, S., Poynter, M. E., Terwindt, E., van Dijk, P., Lamers, W. H., et al. (2017). Arginase 1 deletion in myeloid cells affects the inflammatory response in allergic asthma, but not lung mechanics, in female mice. BMC Pulm. Med. 17 (1), 158. doi:10.1186/s12890-017-0490-7

Cloots, R. H. E., Poynter, M. E., Terwindt, E., Lamers, W. H., and Kohler, S. E. (2018). Hypoargininemia exacerbates airway hyperresponsiveness in a mouse model of asthma. Respir. Res. 19 (1), 98. doi:10.1186/s12931-018-0809-9

Closs, E. I., Basha, F. Z., Habermeier, A., and Förstermann, U. (1997). Interference of $\mathrm{L}$-arginine analogues with $\mathrm{L}$-arginine transport mediated by the $\mathrm{y}+$ carrier hCAT-2B. Nitric Oxide 1 (1), 65-73. doi:10.1006/niox.1996.0106

Curis, E., Nicolis, I., Moinard, C., Osowska, S., Zerrouk, N., Bénazeth, S., et al. (2005). Almost all about citrulline in mammals. J. Amino Acids 29 (3), 177-205. doi:10.1007/s00726-005-0235-4

De Boer, J., Meurs, H., Flendrig, L., Koopal, M., and Zaagsma, J. (2001). Role of nitric oxide and superoxide in allergen-induced airway hyperreactivity after the late asthmatic reaction in Guinea-pigs. Br. J. Pharmacol. 133 (8), 1235-1242. doi:10.1038/sj.bjp.0704191

De Gouw, H. W., Verbruggen, M. B., Twiss, I. M., and Sterk, P. J. (1999). Effect of oral $\mathrm{L}$-arginine on airway hyperresponsiveness to histamine in asthma. Thorax 54 (11), 1033-1035. doi:10.1136/thx.54.11.1033

Downey, D., and Elborn, J. S. (2000). Nitric oxide, iNOS, and inflammation in cystic fibrosis. J. Pathol. 190 (2), 115-116. doi:10.1002/(SICI)10969896(200002)190:2<115::AID-PATH491>3.0.CO;2-V
Elphick, H. E., Demoncheaux, E. A., Ritson, S., Higenbottam, T. W., and Everard, M. L. (2001). Exhaled nitric oxide is reduced in infants with cystic fibrosis. Thorax 56 (2), 151-152. doi:10.1136/thorax.56.2.151

Fike, C. D., Summar, M., and Aschner, J. L. (2014). L-citrulline provides a novel strategy for treating chronic pulmonary hypertension in newborn infants. Acta Paediatr. 103 (10), 1019-1026. doi:10.1111/apa.12707

Förstermann, U., and Sessa, W. C. (2012). Nitric oxide synthases: regulation and function. Eur. Heart J. 33 (7), 829a-837d. doi:10.1093/eurheartj/ ehr304

Gaston, B., Ratjen, F., Vaughan, J. W., Malhotra, N. R., Canady, R. G., Snyder, A. H., et al. (2002). Nitrogen redox balance in the cystic fibrosis airway: effects of antipseudomonal therapy. Am. J. Respir. Crit. Care Med. 165 (3), 387-390. doi:10.1164/ajrccm.165.3.2106006

Grasemann, H., Michler, E., Wallot, M., and Ratjen, F. (1997). Decreased concentration of exhaled nitric oxide (NO) in patients with cystic fibrosis. Pediatr. Pulmonol. 24 (3), 173-177. doi:10.1002/(sici)1099-0496(199709)24: 3<173::aid-ppul2>3.0.co;2-o

Grasemann, H., Ioannidis, I., Tomkiewicz, R. P., de Groot, H., Rubin, B. K., and Ratjen, F. (1998). Nitric oxide metabolites in cystic fibrosis lung disease. Arch. Dis. Child. 78 (1), 49-53. doi:10.1136/adc.78.1.49

Grasemann, H., Gärtig, S. S., Wiesemann, H. G., Teschler, H., Konietzko, N., and Ratjen, F. (1999). Effect of L-arginine infusion on airway NO in cystic fibrosis and primary ciliary dyskinesia syndrome. Eur. Respir. J. 13 (1), 114-118. doi:10. 1183/09031936.99.13111499

Grasemann, H., Grasemann, C., Kurtz, F., Tietze-Schillings, G., Vester, U., and Ratjen, F. (2005a). Oral L-arginine supplementation in cystic fibrosis patients: a placebo-controlled study. Eur. Respir. J. 25 (1), 62-68. doi:10.1183/09031936. 04.00086104

Grasemann, H., Schwiertz, R., Matthiesen, S., Racké, K., and Ratjen, F. (2005b). Increased arginase activity in cystic fibrosis airways. Am. J. Respir. Crit. Care Med. 172 (12), 1523-1528. doi:10.1164/rccm.200502-253OC

Grasemann, H., Kurtz, F., and Ratjen, F. (2006a). Inhaled L-arginine improves exhaled nitric oxide and pulmonary function in patients with cystic fibrosis. Am. J. Respir. Crit. Care Med. 174 (2), 208-212. doi:10.1164/rccm.200509$14390 \mathrm{C}$

Grasemann, H., Schwiertz, R., Grasemann, C., Vester, U., Racké, K., and Ratjen, F. (2006b). Decreased systemic bioavailability of L-arginine in patients with cystic fibrosis. Respir. Res. 7, 87. doi:10.1186/1465-9921-7-87

Grasemann, H., Al-Saleh, S., Scott, J. A., Shehnaz, D., Mehl, A., Amin, R., et al. (2011). Asymmetric dimethylarginine contributes to airway nitric oxide deficiency in patients with cystic fibrosis. Am. J. Respir. Crit. Care Med. 183 (10), 1363-1368. doi:10.1164/rccm.201012-1995OC

Grasemann, H., Dhaliwal, R., Ivanovska, J., Kantores, C., McNamara, P. J., Scott, J., et al. (2015a). Arginase inhibition prevents bleomycin-induced pulmonary hypertension, vascular remodeling, and collagen deposition in neonatal rat lungs. Am. J. Physiol. Lung Cell. Mol. Physiol. 308 (6), L503-L510. doi:10.1152/ ajplung.00328.2014

Grasemann, H., Gonska, T., Avolio, J., Klingel, M., Tullis, E., and Ratjen, F. (2015b). Effect of ivacaftor therapy on exhaled nitric oxide in patients with cystic fibrosis. J. Cyst. Fibros. 14 (6), 727-732. doi:10.1016/j.jcf.2015. 07.001

Grasemann, H., Klingel, M., Avolio, J., Prentice, C., Gonska, T., Tullis, E., et al. (2020). Long-term effect of CFTR modulator therapy on airway nitric oxide. Eur. Respir. J. 55 (1), 1901113. doi:10.1183/13993003.01113-2019

Holguin, F., Comhair, S. A., Hazen, S. L., Powers, R. W., Khatri, S. S., Bleecker, E. R., et al. (2013). An association between L-arginine/asymmetric dimethyl arginine balance, obesity, and the age of asthma onset phenotype. Am. J. Respir. Crit. Care Med. 187 (2), 153-159. doi:10.1164/rccm.201207-1270OC

Holguin, F., Grasemann, H., Sharma, S., Winnica, D., Wasil, K., Smith, V., et al. (2019). L-Citrulline increases nitric oxide and improves control in obese asthmatics. JCI Insight 4 (24), e131733. doi:10.1172/jci.insight.131733

Ichinose, M., Sugiura, H., Yamagata, S., Koarai, A., and Shirato, K. (2000). Increase in reactive nitrogen species production in chronic obstructive pulmonary disease airways. Am. J. Respir. Crit. Care Med. 162 (2), 701-706. doi:10. 1164/ajrccm.162.2.9908132

Jiang, W., Sun, B., Song, X., Zheng, Y., Wang, L., Wang, T., et al. (2015). Arginase inhibition protects against hypoxia-induced pulmonary arterial hypertension. Mol. Med. Rep. 12 (3), 4743-4749. doi:10.3892/mmr.2015.3994 
Jung, C., Grün, K., Betge, S., Pernow, J., Kelm, M., Muessig, J., et al. (2017). Arginase inhibition reverses monocrotaline-induced pulmonary hypertension. Int. J. Mol. Sci. 18 (8), 1609. doi:10.3390/ijms18081609

Kaneko, F. T., Arroliga, A. C., Dweik, R. A., Comhair, S. A., Laskowski, D., and Oppedisano, R., et al. (1998). Biochemical reaction products of nitric oxide as quantitative markers of primary pulmonary hypertension. Am. J. Respir. Crit. Care Med. 158 (3), 917-923. doi:10.1164/ajrccm.158.3.9802066

Kao, C. C., Wedes, S. H., Hsu, J. W., Bohren, K. M., Comhair, S. A., Jahoor, F., et al. (2015). Arginine metabolic endotypes in pulmonary arterial hypertension. Pulm. Circ. 5 (1), 124-134. doi:10.1086/679720

Kenyon, N. J., Last, M., Bratt, J. M., Kwan, V. W., O’Roark, E., and Linderholm, A. (2011). L-arginine supplementation and metabolism in asthma. J. Pharm. 4 (1), 187-201. doi:10.3390/ph4010187

Kharitonov, S. A., O’Connor, B. J., Evans, D. J., and Barnes, P. J. (1995). Allergeninduced late asthmatic reactions are associated with elevation of exhaled nitric oxide. Am. J. Respir. Crit. Care Med. 151 (6), 1894-1899. doi:10.1164/ajrccm. 151.6.7767537

Klinger, J. R., Abman, S. H., and Gladwin, M. T. (2013). Nitric oxide deficiency and endothelial dysfunction in pulmonary arterial hypertension. Am. J. Respir. Crit. Care Med. 188 (6), 639-646. doi:10.1164/rccm.201304-0686PP

Leiper, J., Nandi, M., Torondel, B., Murray-Rust, J., Malaki, M., O’Hara, B., et al. (2007). Disruption of methylarginine metabolism impairs vascular homeostasis. Nat. Med. 13 (2), 198-203. doi:10.1038/nm1543

Liao, S. Y., Showalter, M. R., Linderholm, A. L., Franzi, L., Kivler, C., Li, Y., et al. (2020). 1-Arginine supplementation in severe asthma. JCI Insight 5 (13), e137777. doi:10.1172/jci.insight.137777

Maarsingh, H., Leusink, J., Zaagsma, J., and Meurs, H. (2006). Role of the L-citrulline/L-arginine cycle in iNANC nerve-mediated nitric oxide production and airway smooth muscle relaxation in allergic asthma. Eur. J. Pharmacol. 546 (1-3), 171-176. doi:10.1016/j.ejphar.2006.07.041

Maarsingh, H., Zaagsma, J., and Meurs, H. (2008a). Arginine homeostasis in allergic asthma. Eur. J. Pharmacol. 585 (2-3), 375-384. doi:10.1016/j.ejphar. 2008.02.096

Maarsingh, H., Zuidhof, A. B., Bos, I. S., van Duin, M., Boucher, J. L., Zaagsma, J., et al. (2008b). Arginase inhibition protects against allergen-induced airway obstruction, hyperresponsiveness, and inflammation. Am. J. Respir. Crit. Care Med. 178 (6), 565-573. doi:10.1164/rccm.200710-1588OC

Maarsingh, H., Bossenga, B. E., Bos, I. S., Volders, H. H., Zaagsma, J., and Meurs, H. (2009a). L-arginine deficiency causes airway hyperresponsiveness after the late asthmatic reaction. Eur. Respir. J. 34 (1), 191-199. doi:10.1183/09031936. 00105408

Maarsingh, H., Zaagsma, J., and Meurs, H. (2009b). Arginase: a key enzyme in the pathophysiology of allergic asthma opening novel therapeutic perspectives. $\mathrm{Br}$. J. Pharmacol. 158 (3), 652-664. doi:10.1111/j.1476-5381.2009.00374.x

Maarsingh, H., Dekkers, B. G., Zuidhof, A. B., Bos, I. S., Menzen, M. H., Klein, T., et al. (2011). Increased arginase activity contributes to airway remodelling in chronic allergic asthma. Eur. Respir. J. 38 (2), 318-328. doi:10.1183/09031936. 00057710

Mabalirajan, U., Ahmad, T., Leishangthem, G. D., Joseph, D. A., Dinda, A. K., Agrawal, A., et al. (2010). Beneficial effects of high dose of L-arginine on airway hyperresponsiveness and airway inflammation in a murine model of asthma. J. Allergy Clin. Immunol. 125 (3), 626-635. doi:10.1016/j.jaci.2009. 10.065

Meurs, H., McKay, S., Maarsingh, H., Hamer, M. A., Macic, L., Molendijk, N., et al. (2002). Increased arginase activity underlies allergen-induced deficiency of cNOS-derived nitric oxide and airway hyperresponsiveness. Br. J. Pharmacol. 136 (3), 391-398. doi:10.1038/sj.bjp.0704725

Meurs, H., Maarsingh, H., and Zaagsma, J. (2003). Arginase and asthma: novel insights into nitric oxide homeostasis and airway hyperresponsiveness. Trends Pharmacol. Sci. 24 (9), 450-455. doi:10.1016/S0165-6147(03)00227-X

Montgomery, A. M., Bazzy-Asaad, A., Asnes, J. D., Bizzarro, M. J., Ehrenkranz, R. A., and Weismann, C. G. (2016). Biochemical screening for pulmonary hypertension in preterm infants with bronchopulmonary dysplasia. Neonatology 109 (3), 190-194. doi:10.1159/000442043

Morris, C. R., Kato, G. J., Poljakovic, M., Wang, X., Blackwelder, W. C., Sachdev, V., et al. (2005). Dysregulated arginine metabolism, hemolysis-associated pulmonary hypertension, and mortality in sickle cell disease. JAMA. 294 (1), 81-90. doi:10.1001/jama.294.1.81
Morris, C. R., Morris, S. M., Hagar, W., Van Warmerdam, J., Claster, S., KepkaLenhart, D., et al. (2003). Arginine therapy: a new treatment for pulmonary hypertension in sickle cell disease? Am. J. Respir. Crit. Care Med. 168 (1), 63-69. doi:10.1164/rccm.200208-967OC

Morris, C. R., Poljakovic, M., Lavrisha, L., Machado, L., Kuypers, F. A., and Morris, S. M. (2004). Decreased arginine bioavailability and increased serum arginase activity in asthma. Am. J. Respir. Crit. Care Med. 170 (2), 148-153. doi:10.1164/ rccm.200309-1304OC

Morris, C. R. (2014). Alterations of the arginine metabolome in sickle cell disease: a growing rationale for arginine therapy. Hematol. Oncol. Clin. North. Am. 28 (2), 301-321. doi:10.1016/j.hoc.2013.11.008

Morris, C. R. (2017). Arginine therapy shows promise for treatment of sickle cell disease clinical subphenotypes of hemolysis and arginine deficiency. Anesth. Analg. 124 (4), 1369-1370. doi:10.1213/ANE.0000000000001874

Münzel, T., Daiber, A., Ullrich, V., and Mülsch, A. (2005). Vascular consequences of endothelial nitric oxide synthase uncoupling for the activity and expression of the soluble guanylyl cyclase and the cGMP-dependent protein kinase. Arterioscler Thromb. Vasc. Biol. 25 (8), 1551-1557. doi:10.1161/01.ATV. 0000168896.64927.bb

Nagaya, N., Uematsu, M., Oya, H., Sato, N., Sakamaki, F., Kyotani, S., et al. (2001). Short-term oral administration of L-arginine improves hemodynamics and exercise capacity in patients with precapillary pulmonary hypertension. Am. J. Respir. Crit. Care Med. 163 (4), 887-891. doi:10.1164/ajrccm.163.4.2007116

Niese, K. A., Collier, A. R., Hajek, A. R., Cederbaum, S. D., O’Brien, W. E., WillsKarp, M., et al. (2009). Bone marrow cell derived arginase I is the major source of allergen-induced lung arginase but is not required for airway hyperresponsiveness, remodeling and lung inflammatory responses in mice. BMC Immunol. 10, 33. doi:10.1186/1471-2172-10-33

North, M. L., Grasemann, H., Khanna, N., Inman, M. D., Gauvreau, G. M., and Scott, J. A. (2013). Increased ornithine-derived polyamines cause airway hyperresponsiveness in a mouse model of asthma. Am. J. Respir. Cell Mol. Biol. 48 (6), 694-702.

North, M. L., Khanna, N., Marsden, P. A., Grasemann, H., and Scott, J. A. (2009). Functionally important role for arginase 1 in the airway hyperresponsiveness of asthma. Am. J. Physiol. Lung Cel Mol Physiol 296 (6), L911-L920. doi:10.1152/ ajplung.00025.2009

Osoata, G. O., Hanazawa, T., Brindicci, C., Ito, M., Barnes, P. J., Kharitonov, S., et al. (2009). Peroxynitrite elevation in exhaled breath condensate of COPD and its inhibition by fudosteine. Chest 135 (6), 1513-1520. doi:10.1378/chest.08-2105

Pera, T., Zuidhof, A. B., Smit, M., Menzen, M. H., Klein, T., Flik, G., et al. (2014). Arginase inhibition prevents inflammation and remodeling in a Guinea pig model of chronic obstructive pulmonary disease. J. Pharmacol. Exp. Ther. 349 (2), 229-238. doi:10.1124/jpet.113.210138

Polycarpou, E., Zachaki, S., Polycarpou, N., Gavrili, S., and Kostalos, C. (2013). L-arginine for chronic lung disease (CLD) in preterm neonates. Lausanne, Switzerland: European Respiratory Society: European Respiratory Journal.

Ricciardolo, F. L., Sterk, P. J., Gaston, B., and Folkerts, G. (2004). Nitric oxide in health and disease of the respiratory system. Physiol. Rev. 84 (3), 731-765. doi:10.1152/physrev.00034.2003

Robbins, R. A., Hadeli, K., Nelson, D., Sato, E., and Hoyt, J. C. (2000). Nitric oxide, peroxynitrite, and lower respiratory tract inflammation. Immunopharmacology 48 (3), 217-221. doi:10.1016/s0162-3109(00)00220-4

Roy, K., Borrill, Z. L., Starkey, C., Hazel, A. L., Morris, J., Vestbo, J., et al. (2007). Use of different exhaled nitric oxide multiple flow rate models in COPD. Eur. Respir. J. 29 (4), 651-659. doi:10.1183/09031936.00149706

Saleh, D., Ernst, P., Lim, S., Barnes, P. J., and Giaid, A. (1998). Increased formation of the potent oxidant peroxynitrite in the airways of asthmatic patients is associated with induction of nitric oxide synthase: effect of inhaled glucocorticoid. FASEB J. 12 (11), 929-937. doi:10.1096/fasebj.12.11.929

Sapienza, M. A., Kharitonov, S. A., Horvath, I., Chung, K. F., and Barnes, P. J. (1998). Effect of inhaled L-arginine on exhaled nitric oxide in normal and asthmatic subjects. Thorax 53 (3), 172-175. doi:10.1136/thx.53.3.172

Scott, J. A., and Grasemann, H. (2013). Asymmetric dimethylarginine: a disease marker for asthma? Chest 144 (2), 367-368. doi:10.1378/chest.13-0480

Scott, J. A., North, M. L., Rafii, M., Huang, H., Pencharz, P., Subbarao, P., et al. (2011). Asymmetric dimethylarginine is increased in asthma. Am. J. Respir. Crit. Care Med. 184 (7), 779-785. doi:10.1164/rccm.201011-1810OC 
Scott, J. A., Duongh, M., Young, A. W., Subbarao, P., Gauvreau, G. M., and Grasemann, H. (2014a). Asymmetric dimethylarginine in chronic obstructive pulmonary disease (ADMA in COPD). Int. J. Mol. Sci. 15 (4), 6062-6071. doi:10.3390/ijms15046062

Scott, J. A., Gauvreau, G. M., and Grasemann, H. (2014b). Asymmetric dimethylarginine and asthma. Eur. Respir. J. 43 (2), 647-648. doi:10.1183/ 09031936.00080313

Sharif Kashani, B., Tahmaseb Pour, P., Malekmohammad, M., Behzadnia, N., Sheybani-Afshar, F., Fakhri, M., et al. (2014). Oral 1-citrulline malate in patients with idiopathic pulmonary arterial hypertension and Eisenmenger Syndrome: a clinical trial. J. Cardiol. 64 (3), 231-235. doi:10.1016/j.jjcc. 2014.01 .003

Silvera Ruiz, S., Grosso, C. L., Tablada, M., Cabrera, M., Dodelson de Kremer, R., Juaneda, E., et al. (2020). Efficacy of citrulline supplementation to decrease the risk of pulmonary hypertension after congenital heart disease surgery. A local experience. Rev. Fac. Cien. Med. Univ. Nac. Cordoba 77 (3), 249. doi:10.31053/ 1853.0605.v77.n4.27936

Smith, H. A., Canter, J. A., Christian, K. G., Drinkwater, D. C., Scholl, F. G., Christman, B. W., et al. (2006). Nitric oxide precursors and congenital heart surgery: a randomized controlled trial of oral citrulline. J. Thorac. Cardiovasc. Surg. 132 (1), 58-65. doi:10.1016/j.jtcvs.2006.02.012

Sopi, R. B., Haxhiu, M. A., Martin, R. J., Dreshaj, I. A., Kamath, S., and Zaidi, S. I. (2007). Disruption of NO-cGMP signaling by neonatal hyperoxia impairs relaxation of lung parenchyma. Am. J. Physiol. Lung Cell. Mol. Physiol. 293 (4), L1029-L1036. doi:10.1152/ajplung.00182.2007

Sopi, R. B., Zaidi, S. I., Mladenov, M., Sahiti, H., Istrefi, Z., Gjorgoski, I., et al. (2012). L-citrulline supplementation reverses the impaired airway relaxation in neonatal rats exposed to hyperoxia. Respir. Res. 13, 68. doi:10.1186/1465-9921-13-68

Suzuki, T., Morita, M., Hayashi, T., and Kamimura, A. (2017). The effects on plasma L-arginine levels of combined oral L-citrulline and L-arginine supplementation in healthy males. Biosci. Biotechnol. Biochem. 81 (2), 372-375. doi:10.1080/09168451.2016.1230007

Tajti, G., Gesztelyi, R., Pak, K., Papp, C., Keki, S., Szilasi, M. E., et al. (2017). Positive correlation of airway resistance and serum asymmetric dimethylarginine level in COPD patients with systemic markers of low-grade inflammation. Int. J. Chron. Obstruct. Pulmon. Dis. 12, 873-884. doi:10.2147/COPD.S127373

Vadivel, A., Aschner, J. L., Rey-Parra, G. J., Magarik, J., Zeng, H., Summar, M., et al. (2010). L-citrulline attenuates arrested alveolar growth and pulmonary hypertension in oxygen-induced lung injury in newborn rats. Pediar. Res. 68 (6), 519-525. doi:10.1203/PDR.0b013e3181f90278

van den Berg, M. P. M., Kurhade, S. H., Maarsingh, H., Erceg, S., Hulsbeek, I. R., Boekema, P. H., et al. (2020). Pharmacological screening identifies SHK242 and SHK277 as novel arginase inhibitors with efficacy against allergen-induced airway narrowing in vitro and in vivo. J. Pharmacol. Exp. Ther. 374 (1), 62-73. doi:10.1124/jpet.119.264341
Winnica, D., Que, L. G., Baffi, C., Grasemann, H., Fiedler, K., Yang, Z., et al. (2017) l-citrulline prevents asymmetric dimethylarginine-mediated reductions in nitric oxide and nitrosative stress in primary human airway epithelial cells. Clin. Exp. Allergy 47 (2), 190-199. doi:10.1111/cea.12802

Wu, G., and Morris, S. M. (1998). Arginine metabolism: nitric oxide and beyond. Biochem. J. 336 (1), 1-17. doi:10.1042/bj3360001

Wu, Y. S., Jiang, J., Ahmadi, S., Lew, A., Laselva, O., Xia, S., et al. (2019). ORKAMBI-mediated rescue of mucociliary clearance in cystic fibrosis primary respiratory cultures is enhanced by arginine uptake, arginase inhibition, and promotion of nitric oxide signaling to the cystic fibrosis transmembrane conductance regulator channel. Mol. Pharm. 96 (4), 515-525. doi:10.1124/mol.119.117143

Xu, W., Kaneko, F. T., Zheng, S., Comhair, S. A., Janocha, A. J., Goggans, T., et al. (2004). Increased arginase II and decreased NO synthesis in endothelial cells of patients with pulmonary arterial hypertension. FASEB J. 18 (14), 1746-1748. doi:10.1096/fj.04-2317fje

Xu, W., Ghosh, S., Comhair, S. A., Asosingh, K., Janocha, A. J., Mavrakis, D. A., et al. (2016). Increased mitochondrial arginine metabolism supports bioenergetics in asthma. J. Clin. Invest. 126 (7), 2465-2481. doi:10.1172/ JCI82925

Xu, W., Comhair, S. A. A., Janocha, A. J., Lara, A., Mavrakis, L. A., Bennett, C. D., et al. (2017). Arginine metabolic endotypes related to asthma severity. PLoS One 12 (8), e0183066. doi:10.1371/journal.pone. 0183066

Zhang, R., Kubo, M., Murakami, I., Setiawan, H., Takemoto, K., Inoue, K., et al. (2015). l-Arginine administration attenuates airway inflammation by altering l-arginine metabolism in an NC/Nga mouse model of asthma. J. Clin. Biochem. Nutr. 56 (3), 201-207. doi:10.3164/jcbn.14-140

Zimmermann, N., King, N. E., Laporte, J., Yang, M., Mishra, A., Pope, S. M., et al. (2003). Dissection of experimental asthma with DNA microarray analysis identifies arginase in asthma pathogenesis. J. Clin. Invest. 111 (12), 1863-1874. doi:10.1172/JCI17912

Conflict of Interest: The authors declare that the research was conducted in the absence of any commercial or financial relationships that could be construed as a potential conflict of interest.

Copyright (C) 2021 Scott, Maarsingh, Holguin and Grasemann. This is an open-access article distributed under the terms of the Creative Commons Attribution License (CC $B Y)$. The use, distribution or reproduction in other forums is permitted, provided the original author(s) and the copyright owner(s) are credited and that the original publication in this journal is cited, in accordance with accepted academic practice. No use, distribution or reproduction is permitted which does not comply with these terms. 